\title{
Electron Emission Properties of Silicon-Rich Silicon Oxide Film Prepared by Reactive Magnetron Sputtering Deposition and Rapid Thermal Annealing
}

\author{
Yan Pang ${ }^{a}$, Wei Zhao ${ }^{a}$, Jie Lit, Yuan Yuan ${ }^{b}$,Wenbo Hu* ${ }^{a}$, Shengli Wu ${ }^{a}$, Yongdong Lit $i^{a}$, Shuning Yang ${ }^{b}$ \\ ${ }^{a} X i$ 'an Jiaotong University, School of Electronic Science and Engineering, Key Laboratory for Physical \\ Electronics and Devices of the Ministry of Education, Xi'an, Shaanxi, 710049, China \\ ${ }^{b}$ Kunming institute of physics, Science and Technology on Low-Light-Level Night Vision Laboratory, \\ Kunming, Yunnan, 650223, China
}

Received: June 27, 2019; Revised: November 08, 2019; Accepted: March 2, 2020

\begin{abstract}
Silicon-rich silicon oxide (SRSO) film was prepared through the deposition of $\mathrm{SiO}_{\mathrm{x}}$ film by radio-frequency reactive magnetron sputtering from a $\mathrm{Si}$ target and the subsequent rapid thermal annealing treatment of $\mathrm{SiO}_{x}$ film, and planar-type field emission cathodes based on SRSO film were fabricated. The surface morphologies and electron emission properties of the SRSO films deposited under different $\mathrm{O}_{2} / \mathrm{Ar}$ flow ratios were investigated. The experimental results show that a relatively high $\mathrm{O}_{2} / \mathrm{Ar}$ flow ratio during the deposition of $\mathrm{SiO}_{\mathrm{x}}$ film can lead to the formation of cluster structure in the SRSO film prepared, and the electron emission efficiency of SRSO film rises with the increase of electric field applied. An SRSO-film cathode fabricated under an $\mathrm{O}_{2} / \mathrm{Ar}$ flow ratio of 1:1 with a chamber pressure of $0.21 \mathrm{~Pa}$ has an emission current density of $65.61 \mu \mathrm{A} / \mathrm{cm}^{2}$ and a corresponding emission efficiency of $0.53 \%$ at a bias voltage of $18 \mathrm{~V}$, and it exhibits relatively stable emission and fine emission uniformity.
\end{abstract}

Keywords: silicon-rich silicon oxide film, field emission cathode, electron emission property, magnetron sputtering.

\section{Introduction}

Field emission cathodes have been widely applied in a variety of vacuum electronic devices, such as electron guns $^{1,2}$, ion sources ${ }^{3,4}, \mathrm{X}$-ray sources ${ }^{5,6}$, microwave power sources $^{7,8}$, parallel e-beam lithography systems ${ }^{9}$ and flat panel displays ${ }^{10,11}$. Planar-type field emission cathodes have some advantages including simple structure, relatively easy fabrication process and low extraction voltage in comparison with traditional microtip-type cathodes ${ }^{12-17}$. Among various planar-type field emission cathodes, the cathodes based on silicon-rich silicon oxide (SRSO) film are currently one of the attractive cathodes due to the simple dry process, full compatibility with mature semiconductor integrated circuit technology and easy realization of Si-based electronic devices.

SRSO film is a kind of composite film consisting of Si nanocrystals (nanoclusters, nanoparticles or quantum dots) embedded inside $\mathrm{SiO}_{2}$ matrix. Some research works on SRSO-film cathodes have been carried out in recent years. Planar cathodes based on nanocrystalline silicon (nc-Si) particles covered with thin oxide films were fabricated by pulsed laser ablation, and the energy distribution of emitted electrons and the emission uniformity of these cathodes were analyzed ${ }^{18-22}$. Nc-Si cathodes could generate optically modulated electron emission under pulsed laser irradiation ${ }^{23}$. The emission efficiency of field emission cathodes based on Si quantum dots formed by very-high-frequency plasma enhanced chemical

"e-mail: huwb@mail.xjtu.edu.cn vapor deposition were improved through the thickness optimization, and the annealing and thermal-oxidation treatment of nc-Si film ${ }^{24,25}$. The field emission cathodes based on a multilayer Si-nanodot film as an electron drift layer were fabricated by low-pressure chemical vapor deposition and subsequent thermal oxidation ${ }^{26,27}$. The surface-oxidized silicon nanocrystals could emit electrons with a non-Maxwellian energy distribution ${ }^{28}$. The electron emission from $\mathrm{SiO}_{2}$ film containing multiple-stacked Si quantum dots was enhanced by phosphorus doping ${ }^{29}$.

As mentioned above, researchers have made much progress in the performance improvement of SRSO-film cathodes. However, for SRSO-film cathodes, the intensive study on their preparation technique, microstructure and emission properties are still deficient so far, which becomes a limiting factor in the further performance improvement and practical application. Additionally, magnetron sputtering is an effective preparation method of SRSO film, but the investigation on the cathode based on the magnetron-sputtering-prepared SRSO film acting as an electron acceleration layer has not been reported. In this work, SRSO film was formed through the deposition of $\mathrm{SiO}_{\mathrm{x}}$ film by radio-frequency reactive magnetron sputtering from a $\mathrm{Si}$ target and the subsequent rapid thermal annealing (RTA) treatment of $\mathrm{SiO}_{x}$ film. The surface morphologies and electron emission properties of the as-prepared SRSO films were investigated, and the emission stability and uniformity of the corresponding cathodes were also evaluated. 


\section{Experiment Description}

\subsection{Sample preparation}

$\mathrm{SiO}_{\mathrm{x}}$-film and SRSO-film samples were prepared for morphological characterizations and electron-emission measurements. The $\mathrm{SiO}_{\mathrm{x}}$ film samples were deposited on the polished sides of heavily doped $(0.01 \sim 0.02 \Omega \cdot \mathrm{cm}) n$-type (100) silicon substrates with a thickness of $0.4 \mathrm{~mm}$ by reactive magnetron sputtering from a high-purity (99.99\%) Si target under the conditions of sputtering power of $180 \mathrm{~W}$, substrate temperature of $4500^{\circ} \mathrm{C}$ and chamber pressure of $0.21 \mathrm{~Pa}$ with different $\mathrm{O}_{2} / \mathrm{Ar}$ flow rates. The SRSO film samples were formed by RTA treatment of $\mathrm{SiO}_{x}$ film in $\mathrm{N}_{2}$ ambience at $900{ }^{\circ} \mathrm{C}$ for $60 \mathrm{~min}$ with a temperature-rising rate of $30^{\circ} \mathrm{C} / \mathrm{s}$, during which a phase separation occurs as follows ${ }^{30}$.

$\mathrm{SiO}_{x} \rightarrow \frac{2-x}{2} \mathrm{Si}+\frac{x}{2} \mathrm{SiO}_{2},(0<x<2)$

To fabricate every SRSO-film cathode, we deposited a thin Au film of approximately 10-nm thickness on the surface of an SRSO film as a top electrode and formed a $\mathrm{Ni} / \mathrm{Cu} / \mathrm{Ni}$ multilayer film with a fan-shaped pattern on the $\mathrm{Au}$ film as a contact electrode for enhancing the electrical connection between the top electrode and the lead wire, and also prepared a $\mathrm{Ni} / \mathrm{Cu} / \mathrm{Ni}$ multilayer film as an ohmic-contact bottom electrode on the unpolished side of a silicon substrate. The effective emission area of the as-prepared cathodes was about $0.60 \mathrm{~cm}^{2}$. The detailed fabrication process of an SRSO-film cathode is shown in Figure 1.

\subsection{Characterization and measurement}

For the film samples mentioned above, their surface morphologies were observed by scanning electron microscope (SEM, JEOL JSM-7000F) and atomic force microscope (AFM, Dimension Icon), and their chemical compositions were analyzed by X-ray photoelectron spectroscopy (XPS, ESCALAB 250Xi).

The electron emission properties of the SRSO-film cathodes were measured with an experimental setup, as shown in Figure 2 , in a vacuum chamber $\left(\sim 10^{-4} \mathrm{~Pa}\right)$ in which a piece of indium tin oxide (ITO) glass (or ITO glass coated with a green (a)

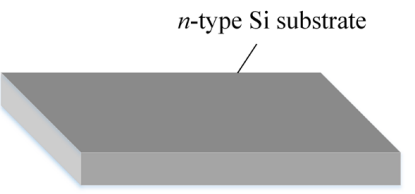

(b)

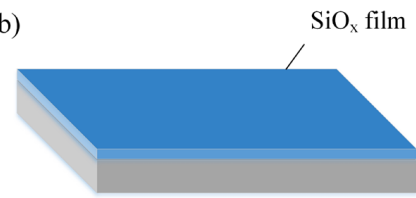

(c)

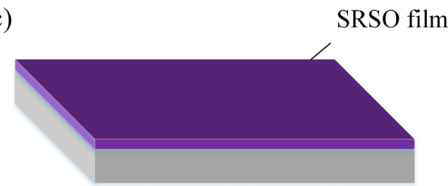

(d)

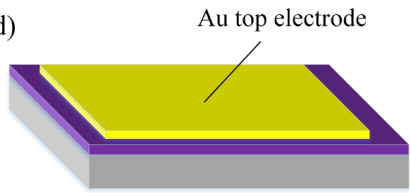

(e)

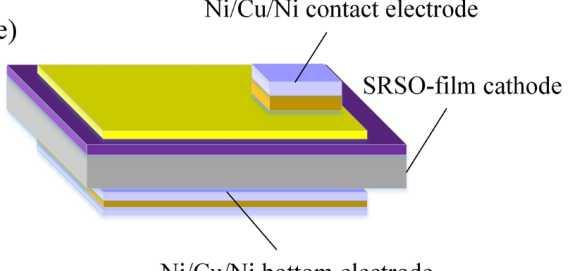

Figure 1. Fabrication process of an SRSO-film cathode: (a) cutting and cleaning of $n$-type Si substrate, (b) $\mathrm{SiO}_{\mathrm{x}}$ film deposition by reactive magnetron sputtering, (c) SRSO film formation through RTA, (d) Au top electrode deposition, and (e) Ni/Cu/Ni electrode deposition.

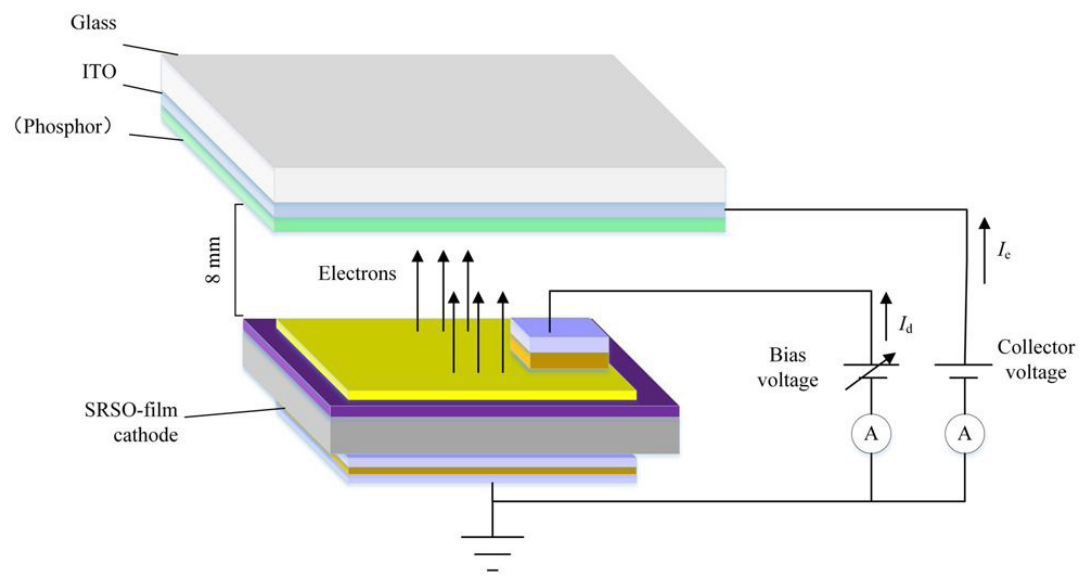

Figure 2. Experimental setup for the measurement of electron emission properties of SRSO-film cathodes. 
phosphor layer in the case of emission-uniformity evaluation) as an electron collector was placed at a distance of $8 \mathrm{~mm}$ from the emission surface of a cathode. During the measurement, a direct current (DC) voltage of $900 \mathrm{~V}$ was applied between the electron collector and the bottom electrode with a high voltage DC power supply (Spellman RHR15PN120), and a bias voltage $V_{\mathrm{b}}$ of $0 \sim 18 \mathrm{~V}$ was employed between the top electrode and the bottom electrode with a DC power analyzer (Agilent N6705A). The diode current $I_{\mathrm{d}}$ and the emission current $I_{\mathrm{e}}$ of a cathode were obtained with the above-mentioned DC power analyzer and a microammeter (Agilent U1252B), respectively. The emission efficiency $\eta$ was defined as the ratio of the emission current to the diode current.

\section{Experimental Results and Discussion}

\subsection{Surface morphologies of SRSO films}

Figure 3 shows the surface and cross-section SEM images of four SRSO-film samples (Sample Nos.: A, B, $\mathrm{C}$ and D) formed through the 180-min depositions under the $\mathrm{O}_{2} /$ Ar flow ratios of $1: 7,1: 3,1: 1$ and $3: 1$, respectively, and the subsequent RTA treatments of $\mathrm{SiO}_{x}$ films. It can be seen that both the samples $\mathrm{A}$ and $\mathrm{B}$ are composed of a large number of nanoparticles, while there appears a distinct cluster structure in the other two samples, especially in Sample D. The clusters consisting of a lot of tiny nanoparticles in the samples C and D mainly have a diameter of $20 \sim 60 \mathrm{~nm}$. This experimental result indicates that a relatively high $\mathrm{O}_{2} / \mathrm{Ar}$ flow ratio during the deposition process of $\mathrm{SiO}_{x}$ film can lead to the formation of cluster structure in the SRSO films prepared. In addition, the thicknesses of the samples A D are $952 \mathrm{~nm}, 328 \mathrm{~nm}, 164 \mathrm{~nm}$ and $230 \mathrm{~nm}$, respectively, due to the variation of $\mathrm{SiO}_{\mathrm{x}}$-film deposition rate under the different $\mathrm{O}_{2} /$ Ar flow ratios.

Figures 4 and 5 show the top-viewed SEM images and AFM images of three thin film samples, respectively. These samples include a $\mathrm{SiO}_{x}$ film (E) deposited under an $\mathrm{O}_{2} / \mathrm{Ar}$ flow ratio of 1:1, an SRSO film (F) formed through the RTA treatment of a $\mathrm{SiO}_{x}$ film being the same as Sample E, and an Au film (G) deposited on an SRSO film being the same as Sample F. It can be seen from Figures $4 \mathrm{a}$ and $4 \mathrm{~b}$ that after RTA treatment, the clusters in the SRSO film have a more uniform size but a relatively blurred cluster structure in comparison with those in the $\mathrm{SiO}_{\mathrm{x}}$ film, which makes the SRSO film have a very smooth surface, as shown in Figures $5 \mathrm{a}$ and $5 \mathrm{~b}$. In accordance with Figures $4 \mathrm{c}$ and $5 \mathrm{c}$, the Au film deposited on the SRSO film is a continuous thin film consisting of a large quantity of Au nanoparticles and has a surface root-mean-square roughness $(\mathrm{Rq})$ of $2.65 \mathrm{~nm}$, so it can play a good role as a top electrode in the SRSO cathode.

The four samples A D mentioned above were also examined by XPS after they had been etched by argon

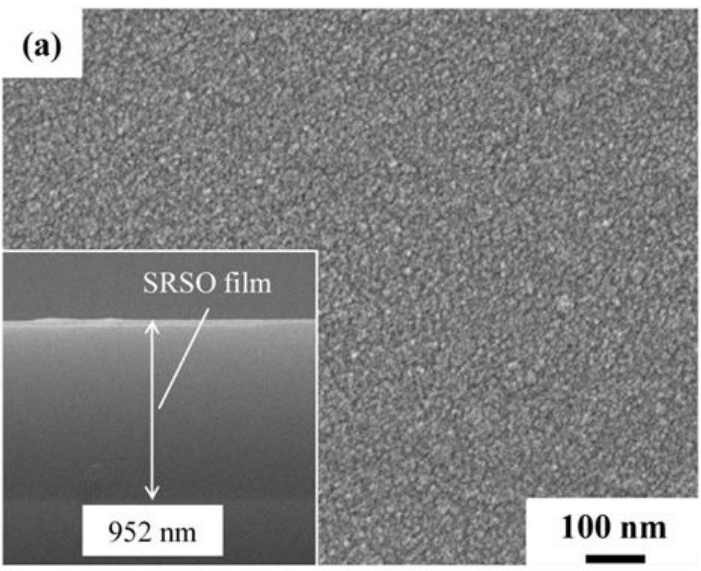

\section{(b)}
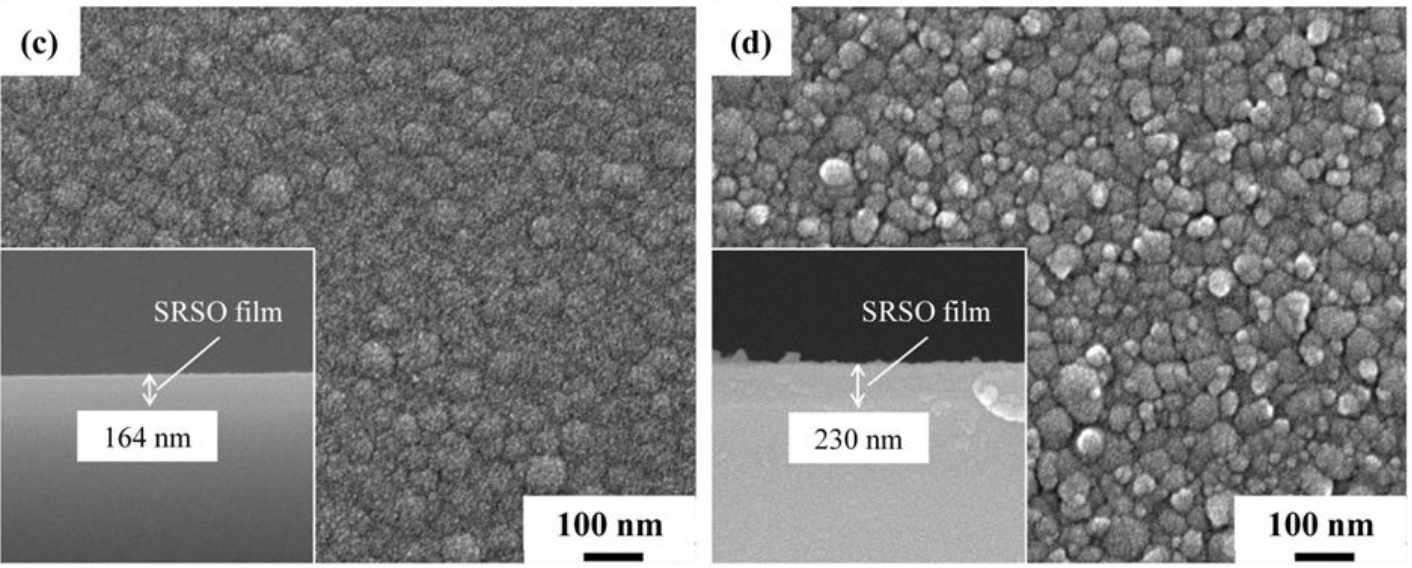

Figure 3. SEM images of four SRSO-film samples prepared under the $\mathrm{O}_{2} / \mathrm{Ar}$ flow ratios of (a) 1:7, (b) 1:3, (c) 1:1, and (d) 3:1 with a chamber pressure of $0.21 \mathrm{~Pa}$, respectively. 

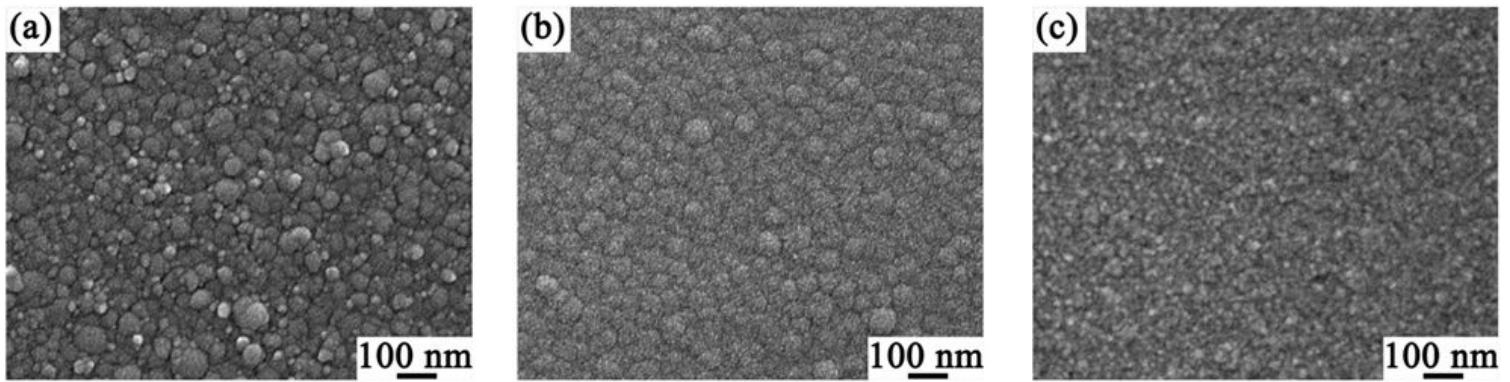

Figure 4. Top-viewed SEM images of (a) a $\mathrm{SiO}_{\mathrm{x}}$ film, (b) an SRSO film, and (c) an Au film deposited on an SRSO film.
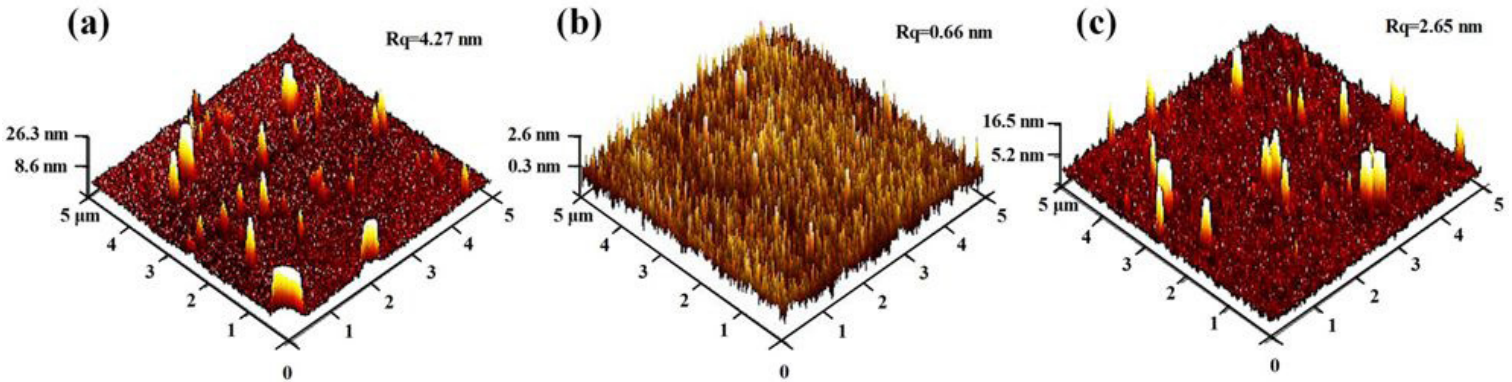

Figure 5. AFM images of (a) a $\mathrm{SiO}_{x}$ film, (b) an SRSO film, and (c) an Au film deposited on an SRSO film.
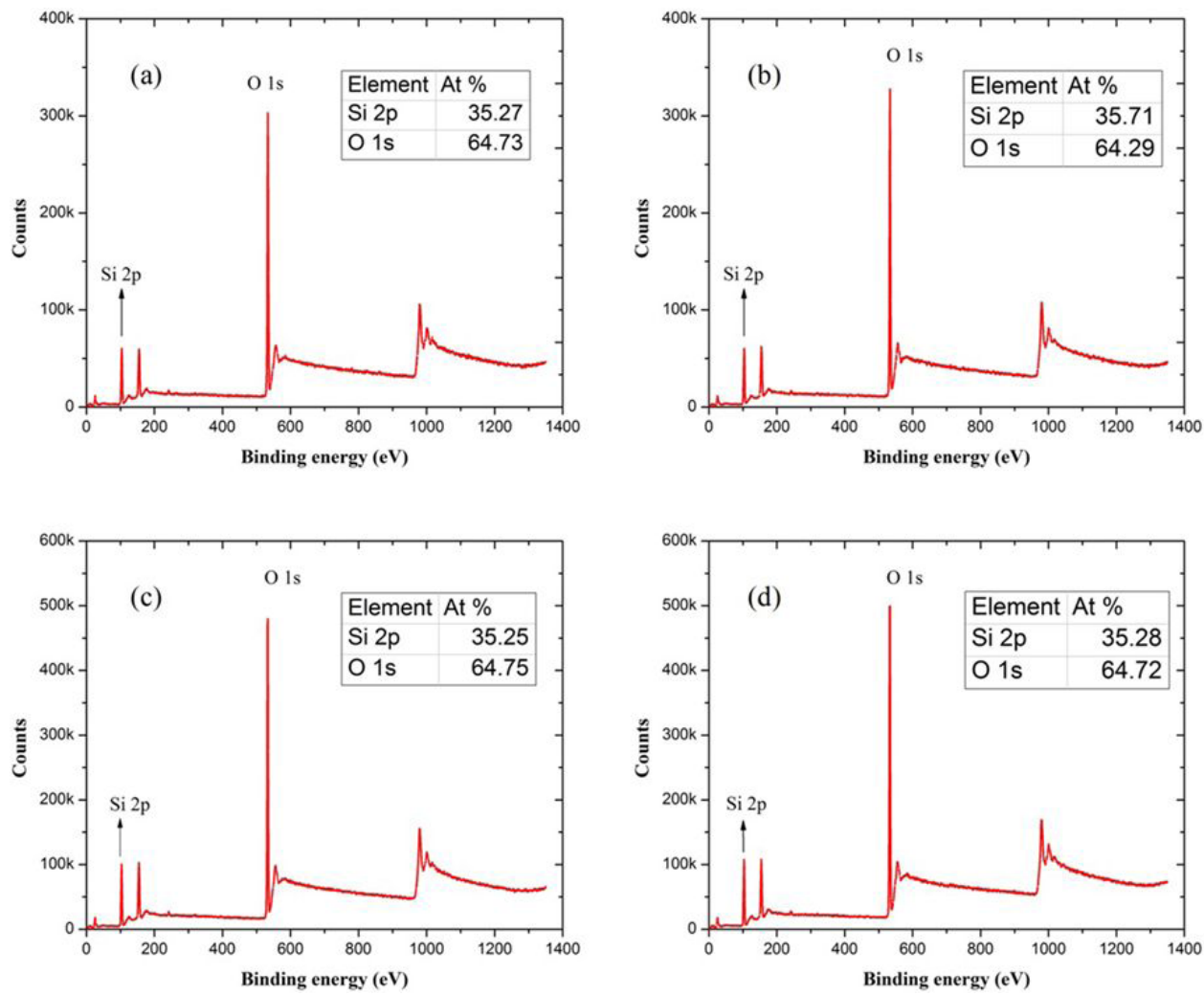

Figure 6. XPS spectra of four SRSO-film samples prepared under the $\mathrm{O}_{2} / \operatorname{Ar}$ flow ratios of (a) 1:7, (b) 1:3, (c) 1:1, and (d) 3:1 with a chamber pressure of $0.21 \mathrm{~Pa}$, respectively.

ions for $60 \mathrm{~s}$ for removing gases absorbed during the storage in the air. According to the analysis results shown in Figure 6, the atomic ratios of $\mathrm{Si}$ to $\mathrm{O}$ in these samples are $1: 1.84,1: 1.80,1: 1.84$ and $1: 1.83$, respectively, which indicates that all these samples are silicon-rich silicon oxide films, and the $\mathrm{O}_{2} / \mathrm{Ar}$ flow ratio in a range of 1:7 3:1 has little effect on the chemical composition of SRSO film. 


\subsection{Electron emission properties of SRSO-film cathodes}

The electron emission properties of the samples A D were measured. Figure 7 shows the dependences of the diode current density $J_{\mathrm{d}}$, emission current density $J$ and emission efficiency $\eta$ on the electric field intensity $E_{\mathrm{b}}$ (=bias voltage $V_{\mathrm{b}} /$ SRSO film thickness) externally applied for these samples. $J_{\mathrm{d}}$ and $J_{\mathrm{e}}$ were calculated in terms of $I_{\mathrm{d}}, I_{\mathrm{e}}$ and the effective emission area. All these samples have basically similar variation tendencies of $J_{\mathrm{d}}, J_{\mathrm{e}}$ and $\eta$ with $E_{\mathrm{b}}$. As the electric field enhances, the diode current density firstly rapidly increases and reaches the maximum value, and then it changes little or even slightly decreases, while both the emission current density and efficiency increase monotonously. The dependence of $J_{\mathrm{d}}$ on $E_{\mathrm{b}}$ does not follow a normally continuously increasing tendency, which is probably connected with the electron trapping caused by Si-nanoparticle $/ \mathrm{SiO}_{2}$ interface defects existing in the SRSO film. The trapped electrons generate a built-in electric field whose direction is opposite to that of the electric field applied. When the built-in electric field increases to a certain extent, the transportation of free electrons inside the film is markedly affected, which makes the diode current increase no more.
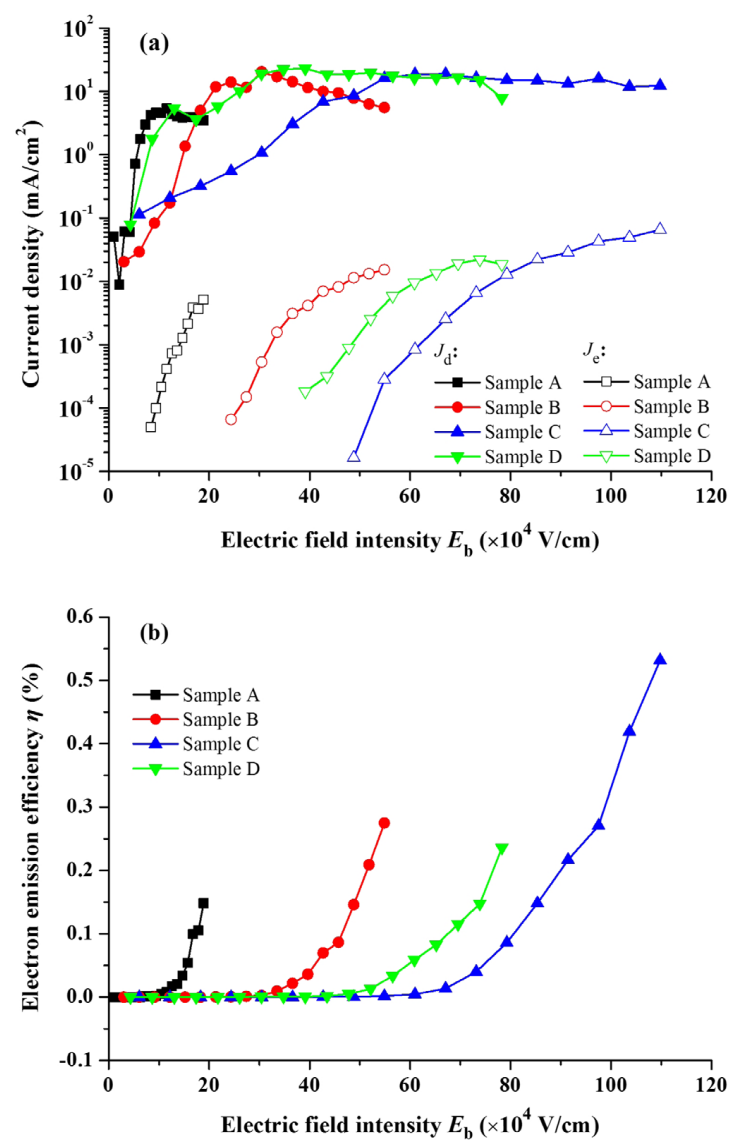

Figure 7. Dependences of (a) diode current density $J_{\mathrm{d}}$ and emission current density $J_{\mathrm{e}}$, and (b) emission efficiency $\eta$ on electric field intensity $E_{\mathrm{b}}$ applied for four SRSO-film cathodes (A $\sim$ D) prepared under the $\mathrm{O}_{2} /$ Ar flow ratios of $1: 7,1: 3,1: 1$, and 3:1, respectively.
This factor also slightly slows down the increasing rate of the emission current with the electric field applied.

The samples A $\sim \mathrm{D}$ have the emission current densities of $5.13 \mu \mathrm{A} / \mathrm{cm}^{2}, 15.17 \mu \mathrm{A} / \mathrm{cm}^{2}, 65.61 \mu \mathrm{A} / \mathrm{cm}^{2}$, and $18.56 \mu \mathrm{A} / \mathrm{cm}^{2}$, respectively, at $18 \mathrm{~V}$ with their corresponding efficiencies of $0.15 \%, 0.27 \%, 0.53 \%$, and $0.24 \%$, so Sample C has the maximum emission current density and efficiency among these samples. This result may have a relationship with the thinnest thickness of the SRSO film of Sample C, which make the free electrons in the SRSO film suffer less scattering during their transportation. However, the SRSO film should not be too thin either, otherwise the film breakdown occur easily. In order to make a SRSO film obtain further enhanced emission current density and efficiency, the issue of diode current density saturation should be solved.

The Fowler-Nordheim (F-N) plots of these four samples are shown in Figure 8. The approximate linearity presented by the F-N plots suggests that the mechanism of electron emission from the SRSO film prepared by magnetron sputtering and RTA is a field-induced electron tunneling process. SRSO films have a structure which contains a large quantity of $\mathrm{Si}$ nanoparticles scattered in $\mathrm{SiO}_{2}$ dielectric films. When a proper positive bias voltage is applied between the top electrode and the bottom electrode of an SRSO-film cathode, strong electric field forms in the $\mathrm{SiO}_{2}$ dielectric layers between the longitudinally adjacent two Si nanoparticles, especially on the external surfaces of Si nanoparticles, which causes that the electrons injected into the SRSO film mainly pick up energy in the $\mathrm{SiO}_{2}$ dielectric layers and cross over Si-nanoparticle/ $\mathrm{SiO}_{2}$ interfacial potential barriers from Si nanoparticles into $\mathrm{SiO}_{2}$ layers by tunneling effect. After going through a series of accelerations and tunnelings in the SRSO film, the electrons reaching the top electrode will be emitted into vacuum if they have the enough energy higher than the surface potential barrier of the cathode.

Figure 9 shows the variations of the diode and emission current densities with time at a bias voltage of $18 \mathrm{~V}$ for the samples A, B, C and D. The diode and emission current densities of these samples basically keep stable during the

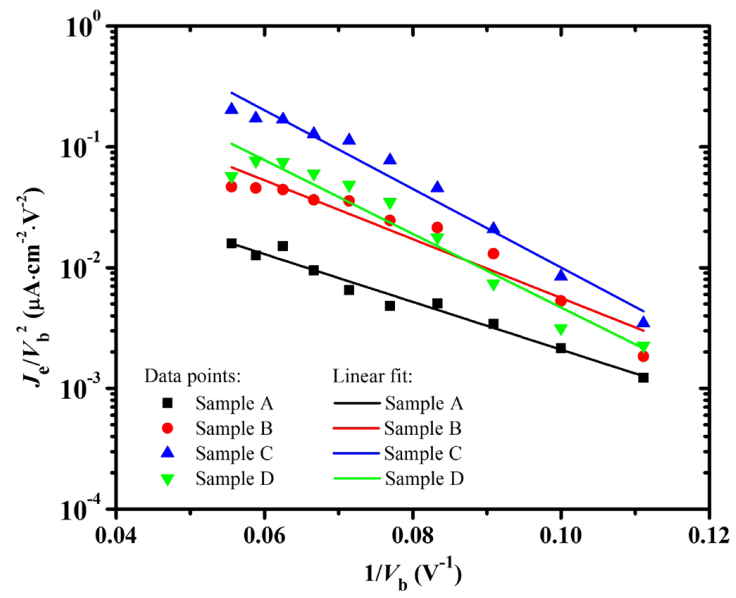

Figure 8. Fowler-Nordheim plots of four SRSO-film cathodes $(\mathrm{A} \sim \mathrm{D})$ prepared under the $\mathrm{O}_{2} / \mathrm{Ar}$ flow ratios of $1: 7,1: 3,1: 1$, and $3: 1$, respectively. 


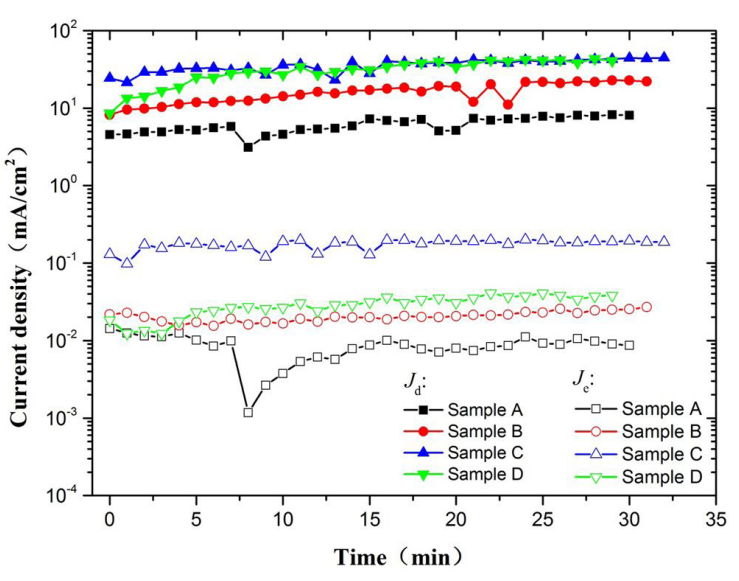

Figure 9. Variations of the diode and emission current densities with time at a bias voltage of $18 \mathrm{~V}$ for four SRSO-film cathodes $(A \sim D)$ prepared under the $\mathrm{O}_{2} /$ Ar flow ratios of 1:7, 1:3, 1:1, and 3:1, respectively.

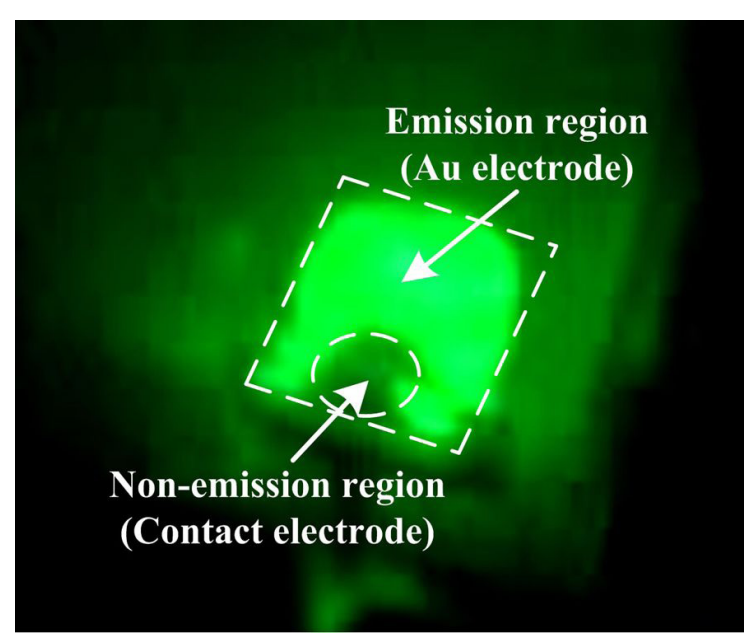

Figure 10. Luminescence image of green phosphor excited by the emission electrons from an SRSO-film cathode (Sample C).

30-min testing process, except for the electron emission of Sample A in the initial period. Hence on the whole the SRSO cathodes have a favourable emission stability.

Since Sample C has the maximum emission current among these four samples, its electron emission uniformity was further evaluated. Figure 10 shows the luminescence image of green phosphor excited by the emission electrons from Sample C. It can be seen that the luminescence is bright and uniform, and its pattern is in coincidence with the effective emission region of Sample C. This experimental result suggests that the SRSO-film cathode formed by magnetron sputtering and RTA has a good emission uniformity due to its simple structure and precisely controllable preparation process of SRSO film.

The SRSO film prepared by magnetron sputtering and RTA was verified preliminarily as a field-induced electron emission material in this work, and the improvement of its electron emission performance (especially in emission current density and efficiency) through the deep analysis of relative factors and the optimization of preparation technique and microstructure of SRSO film will be our further work.

\section{Conclusions}

To explore the preparation and performance of a kind of Si-based thin-film field-emission cathode, the cathodes based on SRSO film were prepared by radio-frequency reactive magnetron sputtering deposition and subsequent rapid thermal annealing of $\mathrm{SiO}_{\mathrm{x}}$ film, and their electron emission properties were investigated. A relatively high $\mathrm{O}_{2} / \mathrm{Ar}$ flow ratio during the deposition of $\mathrm{SiO}_{\mathrm{x}}$ film is beneficial to the formation of nanoclusters in the SRSO film. An SRSO-film cathode fabricated under an $\mathrm{O}_{2} / \mathrm{Ar}$ flow ratio of 1:1 with a chamber pressure of $0.21 \mathrm{~Pa}$ has an emission current density of $65.61 \mu \mathrm{A} / \mathrm{cm}^{2}$ at $18 \mathrm{~V}$ with an emission efficiency of $0.53 \%$, and it also has good emission stability and uniformity. The SRSO-film cathode formed by magnetron sputtering and RTA has preliminarily exhibited its potential as a kind of favourable planar-type field emission cathode, and its performance will be ameliorated through the improvement of preparation technique and microstructure of SRSO film.

\section{Acknowledgments}

This work was supported by the National Natural Science Foundation of China under Grant Nos. U1537210 and 61275023, and the Foundation of the Key Laboratory under Grant No. 614241204021703.

\section{References}

1. Yuan XS, Zhang Y, Cole MT, Yan Y, Li XY, Parmee R, et al. A truncated-cone carbon nanotube cold-cathode electron gun. Carbon. 2017;120:374-9.

2. Yuan XS, Zhang Y, Yang H, Li XY, Xu NS, Deng SZ, et al. A gridded high-compression-ratio carbon nanotube cold cathode electron gun. IEEE Electron Device Lett. 2015;36(4):399-401.

3. Cun HY, Spescha A, Schuler A, Hengsberger M, Osterwalder J, Greber T. Characterization of a cold cathode Penning ion source for the implantation of noble gases beneath 2D monolayers on metals: ions and neutrals. J Vac Sci Technol A. 2016;34:020602.

4. Reheem AMA, Ahmed MM, Abdelhamid MM, Ashour AH. Verification of high efficient broad beam cold cathode ion source. Rev Sci Instrum. 2016;87:083302.

5. Jeong JW, Kim JW, Kang JT, Choi S, Ahn S, Song YH. A vacuumsealed compact X-ray tube based on focused carbon nanotube field-emission electrons. Nanotechnology. 2013;24:085201.

6. Alivov Y, Klopfer M, Molloi S. TiO nanotubes as a cold cathode for X-ray generation. Appl Phys Lett. 2010;96:243502.

7. Wang SM, Aditya S, Miao JM, Xia X. Design of a sheet-beam electron-optical system for a microfabricated W-band travelingwave tube using a cold cathode. IEEE Trans Electron Dev. 2016;63(9):3725-32.

8. Li SG, Yan TC, Li FL, Yang JS, Shi W. Experimental study of millimeter magnetrons with cold cathodes. IEEE Trans Plasma Sci. 2016;44(8):1386-90.

9. Chen YC, Deng SZ, Xu NS, Chen J. Origin of the ring-shaped emission pattern observed from the field emission of $\mathrm{ZnO}$ nanowire: role of adsorbates and electron initial velocity. Mater Res Express. 2014;1:045050

10. Chen J, Dai YY, Luo J, Li ZL, Deng SZ, She JC, et al. Field emission display device structure based on double-gate driving principle for achieving high brightness using a variety of field emission nanoemitters. Appl Phys Lett. 2007;90:253105. 
11. Liu P, Wei Y, Liu K, Liu L, Jiang KL, Fan SS. New-type planar field emission display with superaligned carbon nanotube yarn emitter. Nano Lett. 2012;12:2391-6.

12. Xu NS, Huq SE. Novel cold cathode materials and applications. Mater Sci Eng Rep. 2005;48:47-189.

13. Hu WB, Zhao W, Fan JL, Wu SL, Zhang JT. Emission properties of porous silicon electron emitters formed by pulsed anodic etching. J Electron Mater. 2017;46(2):895-902.

14. Noda D, Hagiwara K, Yamamoto T, Okamoto S. Electron emission properties of $\mathrm{ZnS}$-based thin-film cold cathode for field emission display. Jpn J Appl Phys. 2005;44(6A):4108-11.

15. Wang ZM, Li DJ. A thin-film field-emission cathode with Pt or $\mathrm{Au}$ interlayer between insulator and $\mathrm{Zn}_{0.75} \mathrm{Mg}_{0.25} \mathrm{O}$. Phys Status Solidi. 2007;204(4):1227-31.

16. Hu WB, Zhao XL, Fan JL, Wu SL, Zhang JT. Electron emission properties of cold cathodes based on porous silicon layer processed by electrochemical oxidation and high pressure water vapor annealing. J Porous Mater. 2015;22:761-7.

17. Kusunoki T, Suzuki M. Increasing emission current from MIM cathodes by using an Ir-Pt-Au multilayer top electrode. IEEE Trans Electron Dev. 2000;47(8):1667-72.

18. Shimawaki H, Murakami K, Neo Y, Mimura H, Wakaya F, Takai M. Evaluation of emission uniformity of nanocrystalline silicon planar cathodes. J Vac Sci Technol B. 2010;28(2):C2C49-52.

19. Shimawaki H, Neo Y, Mimura H. Electron emission from planar-type cathodes based on nanocrystalline silicon thin films. J Vac Sci Technol B. 2006;24(2):971-3.

20. Shimawaki H, Neo Y, Mimura H, Murakami K, Wakaya F, Takai M. Emission properties of nanocrystalline silicon planar cathodes. In: 14th International Display Workshops; 2007 Dec 3-5; Sapporo, Japan. Proceedings. Japan: Institute of Image Information and Television Engineers; 2007. p. 2217-9.

21. Shimawaki H, Murakami K, Neo Y, Mimura H, Wayaka F, Takai M. Intensity distribution of electron emission from nc-Si MOS cathode. In: 16th International Display Workshops; 2009 Dec
9-11; Fukuoka, Japan. Proceedings. Japan: Institute of Image Information and Television Engineers; p. 2001-4.

22. Shimawaki H, Neo Y, Mimura H, Murakami K, Wakaya F, Takai M. Improvement of emission efficiency of nanocrystalline silicon planar cathodes. J Vac Sci Technol B. 2008;26(2):864-7.

23. Shimawaki H, Neo Y, Mimura H, Wakaya F, Takai M. Photoassisted electron emission from metal-oxide-semiconductor cathodes based on nanocrystalline silicon. J Appl Phys. 2013;113:153705.

24. Nishiguchi K, Zhao X, Oda S. Nanocrystalline silicon electron emitter with a high efficiency enhanced by a planarization technique. J Appl Phys. 2002;92(5):2748-57.

25. Nishiguchi K, Zhao X, Oda S. Fabrication and characterization of cold electron emitter based on nanocrystalline silicon dots. In: 2000 Materials Research Society Symposium; 2000 Nov 30 - Dec 3; Boston, Massachusetts, USA. Proceedings. Warrendale: Materials Research Society; 2000. p. 591-5.

26. Hirano Y, Nanba M, Egami N, Yamazaki S, Koshida N. Development of dry-processed silicon nanodot planar cold cathode and its electron emission properties. J Vac Sci Technol B. 2010;28(2):C2B6-10.

27. Takeuchi D, Makihara K, Ohta A, Ikeda M, Miyazaki S. Characterization of electron emission from high density selfaligned Si-based quantum dots by conducting-probe atomic force microscopy. ECS Trans. 2014;64(6):923-8.

28. Oda S, Huang SY, Salem MA, Hippo D, Mizuta H. Charge storage and electron/light emission properties of silicon nanocrystals. Physica E. 2007;38:59-63.

29. Takeuchi D, Makihara K, Ohta A, Ikeda M, Miyazaki S. Impact of phosphorus doping to multiple-stacked Si quantum dots on electron emission properties. Mater Sci Semicond Process. 2017;70:183-7.

30. Hinds BJ, Wang F, Wolfe DM, Hinkle CL, Lucovsky G. Study of $\mathrm{SiO}$ decomposition kinetics and formation of $\mathrm{SiO}_{x}$ nanocrystals in an $\mathrm{SiO}$ matrix. J Non-Cryst Solids. 1998;227230:507-12. 